This item was submitted to Loughborough's Research Repository by the author.

Items in Figshare are protected by copyright, with all rights reserved, unless otherwise indicated.

\title{
Degradation studies of crosslinked polyethylene. 2, Aged in water
}

PLEASE CITE THE PUBLISHED VERSION

https://doi.org/10.1179/174328905X55623

PUBLISHER

(C) Maney Publishing

LICENCE

CC BY-NC-ND 4.0

\section{REPOSITORY RECORD}

Amato, L., Marianne Gilbert, and Andrew Caswell. 2007. "Degradation Studies of Crosslinked Polyethylene. 2, Aged in Water". figshare. https://hdl.handle.net/2134/2997. 
This item was submitted to Loughborough's Institutional Repository by the author and is made available under the following Creative Commons Licence conditions.

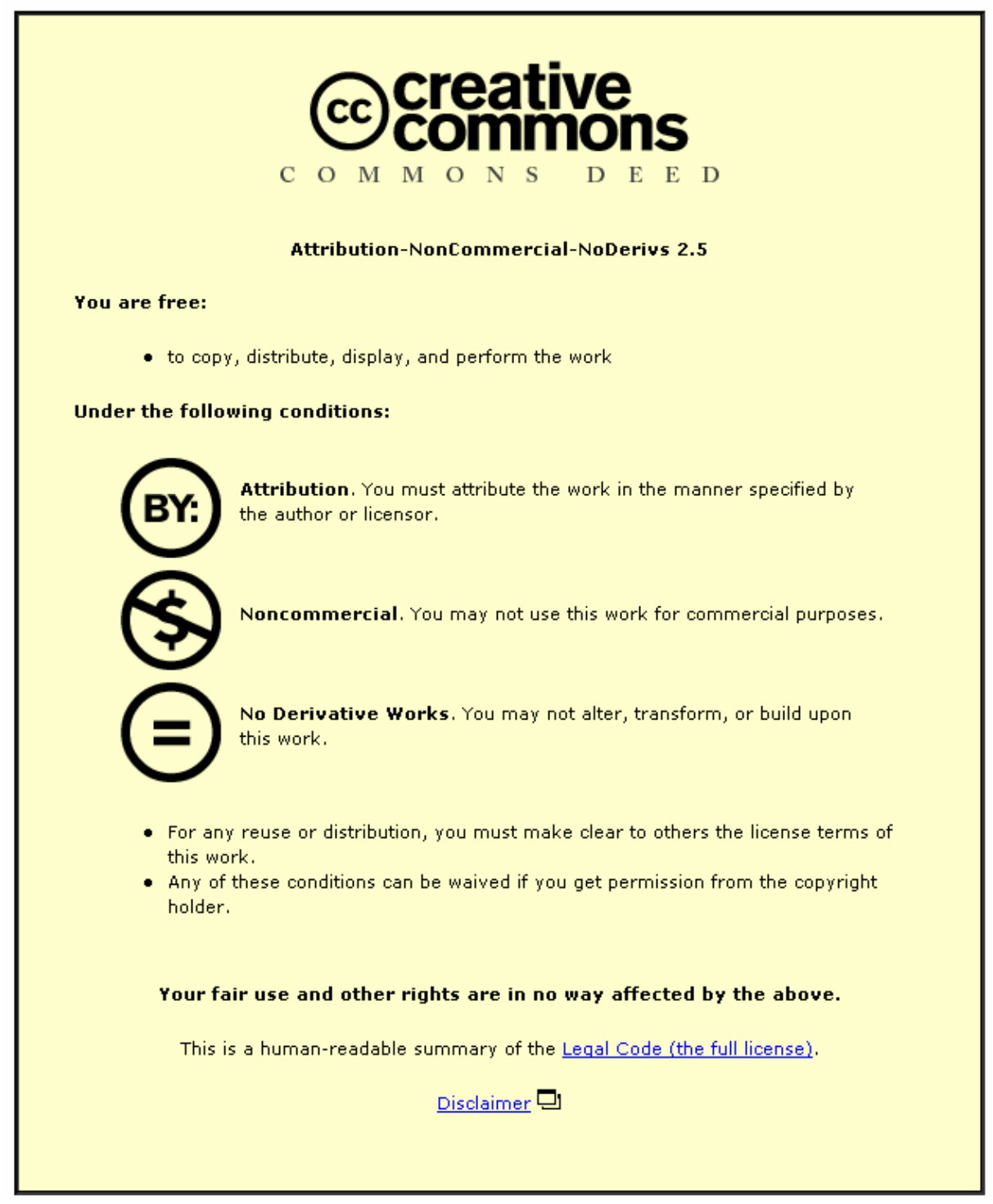

For the full text of this licence, please go to: http://creativecommons.org/licenses/by-nc-nd/2.5/ 


\title{
Degradation Studies of Crosslinked Polyethylene. 2. Aged in water
}

\author{
L. Amato ${ }^{\mathrm{a}}, \mathrm{M}$. Gilbert ${ }^{\mathrm{a}}$, A. Caswell ${ }^{\mathrm{b}}$ \\ ${ }^{a}$ Institute of Polymer Technology and Materials Engineering, Loughborough University, LE11 3TU, Loughborough, UK \\ e-mail: L.Amato@lboro.ac.uk; $\underline{\text { M.Gilbert@lboro.ac.uk }}$ \\ ${ }^{b}$ Wavin Plastics Ltd, Parsonage Way Ind. Est, Chippenham, Wilts., SN15 5PN, UK \\ e-mail: andrew.caswell@wavin.co.uk
}

\begin{abstract}
Silane crosslinking of polyethylene was carried out by grafting an organofunctional silane (vinyltrimethoxysilane) onto polyethylene and by subsequent moisture crosslinking in hot water using a tin catalyst. This study focuses on the degradation processes, which occurred in the material after water ageing in an autoclave; ageing temperatures ranged from 90 to $190^{\circ} \mathrm{C}$, while ageing times ranged from $2 \mathrm{~h}$ to $500 \mathrm{~h}$. Significant changes in the chemical structure of the material were observed by FTIR, as carbonyl group concentration increased and different structures formed in the region of absorbance of groups containing silicone; the structural changes affected significantly the mechanical properties as shown by the tensile data. A chemical analysis of the extracts in chloroform of water aged samples carried out by using FTIR, LIMA and GPC techniques and some optical microscopy evidence, suggested that the mechanism of degradation in water is different from the one in air, as during water ageing the antioxidants are washed away by water and hydrolytic oxidation also occurs. ECHIP experimental design software was used in order to optimise the number of experimental trials and to model the results obtained.
\end{abstract}

Keywords: PE-crosslink, water ageing, carbonyl ratio, silane, antioxidants.

\section{Introduction}

The improvement of thermo-mechanical properties by silane crosslinking of polyethylene makes this material very attractive for the pipe industry, where applications involve elevated temperatures for long times, as a lifetime of 50 years is generally required for a pipe. 
When polyethylene has to be used in long-term applications such as pipe applications, antioxidants are incorporated into the polymers, phenols being used in most cases. Modern antioxidants may be divided into two main groups according to their stabilizing action [1]: chain-breaking or primary antioxidants and preventive or secondary antioxidants. Primary antioxidants interfere with the propagation step of the radical reactions involved in thermooxidation by different radical deactivation mechanisms. Hindered phenols belong to this group and are commonly used in polyolefin grades for hot-water pipes. Hydrogen donors react with peroxy radicals to form hydroperoxides, preventing the abstraction of hydrogen from the polymer backbone [2]. Phenolic stabilizers are the most widely used stabilizers of this type. Secondary antioxidants decompose hydroperoxides to inactive products. Trivalent phosphorus compounds are excellent hydroperoxide decomposers; generally, phosphites (or phosphonites) are used. Some of these compounds are sensitive to water and can hydrolyse, leading to formation of acids. While addition of acid scavenger can minimize the effect in polyolefins, industry has generally converted to hydrolysis-resistant compounds. Typical antioxidant systems used in polyolefin hot-water pipes are hindered phenols combined with secondary antioxidants, such as phosphites or thioesters. A number of tests have been devised for measuring the efficiency of antioxidants; changes in the polymer can be noted by measurements of such properties as carbonyl content (by infra-red measurements), gel content, melt flow index, oxygen uptake. It is known that antioxidants are consumed chemically by the intervening reactions that prevent oxidation of the polymer and by losses to surrounding media either by evaporation or by aqueous extraction.

Three different stages of fracture occur in crosslinked polyethylene pipes $[3,4]$. When large defects are not present there is a ductile fracture (stage 1); in that case there are no significant chemical effects in the polymer. At low stresses the fracture is brittle (stage 2) as a large number of fibrils are present at fracture surfaces, although there is no chemical degradation. When the 
material is also chemically degraded the failure is again brittle (stage 3). The transition from stage 1 failure to brittle fracture occurs at shorter times for crosslinked polyethylene pipe with low gel content and at progressively longer times for pipes of materials with higher gel content. All three types of failure occur in crosslinked polyethylene pipes, but only those with gel content lower than $70 \%$ show stage 2 failure. The great number of interlamellar tie chains of highly crosslinked polyethylene gives this material very high fracture toughness. While stage 2 fracture surfaces contain many ruptured fibrils, stage 3 failure is initiated at spots of highly oxidised material in the absence of fibrils. These spots are due to contaminant particles that catalyse degradation (metal ions, for example) or to poor dispersion with areas of depleted antioxidant. An Arrhenius relationship between temperature and stage 3 life (plot of reciprocal absolute temperature against the log of failure time) has been found in cases where there is an excess of oxygen $[5,6]$.

The mechanism of stage 3 failure can be divided into three different regimes [7,8]. In the regime A the antioxidant dissolved in a polyethylene extrudate precipitates from a supersaturated solution. At normal polyethylene processing temperatures of about $200^{\circ} \mathrm{C}$, the solubility of antioxidant is much greater than at room temperature or during hydrostatic pressure testing; after extrusion, the pipe is cooled rapidly, reducing the solubility of the antioxidant, inducing then a thermodynamic driving force for precipitation. When the antioxidant is segregated into a separate phase, it no longer contributes to the stabilisation of the polymer. In regime B antioxidant diffuses to the surface of the pipe and is either washed away or evaporates, this process is much slower compared with the previous regime and the rate at which occurs is determined by several factors, such as the nature of the antioxidant, additional fillers or additives and dimensions of the pipe. The most important conclusion that can be drawn is that the loss of antioxidant by diffusion depends linearly on time [9]. When all the antioxidant is consumed thermo-oxidative degradation of the polymer occurs (regime C). 
The inherent stability of polyethylene will determine the time to failure. Lifetime predictions for pipes are usually based on data obtained by long-term hydrostatic pressure testing at elevated temperatures, where the testing conditions are very similar to the service conditions [10]. These tests do not actually predict the anticipated lifetime but instead ensure that the creep-rupture strength of the pipe maintains a specified value for at least 50 years.

A previous paper examined the air ageing of crosslinked polyethylene (11). The objective of this work was to investigate the structural changes occurring in the material during ageing in water, in order to understand the mechanism of degradation affecting the properties.

\section{Experimental}

Strips $(17.5 \mathrm{~cm} \times 2.7 \mathrm{~cm} \times 1.5 \mathrm{~mm})$ of silane crosslinked polyethylene (P471+P512/CMB) supplied by MICROPOL Ltd were used for the experimental work [12]. The material contains three different antioxidants supplied by CIBA Ltd: a phenolic one acting as a primary antioxidant and two phosphites as secondary antioxidants. The samples were aged in water in a non-agitated Baskerville autoclave supplied by Wavin Plastics Ltd; ageing temperatures ranged from 90 to $190^{\circ} \mathrm{C}$, while ageing times ranged from $2 \mathrm{~h}$ to $500 \mathrm{~h}$. ECHIP software for experimental design was used in order to optimise the number of experimental trials to be performed and to model the experimental results obtained. A partial cubic model with two inputs (ageing time and ageing temperature) and three outputs (carbonyl ratio, percentage crystallinity and yield strength) seemed to be the most appropriate to fit the results. Water aged samples were characterized by using a FTIR spectrometer MATTSON 3000, by using a Differential Scanning Calorimeter 2010 supplied by TA Instruments and an Hounsfield testing machine for tensile tests; the experimental procedures used have been described previously in an air ageing programme [11].

A ZEISS Universal optical microscope was used in order to observe in polarized and ordinary light how the ageing and degradation process affected the microstructure in the samples. 
In order to extract the antioxidants, some water aged samples were refluxed in $40 \mathrm{ml}$ of boiling chloroform for $2 \mathrm{~h}$ and then a set of experiments was carried out on the extracts, after drying them for $2 \mathrm{~h}$ in a fume cupboard.

FTIR analysis was carried out on the dry residues after mixing them with approximately $100 \mathrm{mg}$ of dry, powdered $\mathrm{KBr}$ to produce discs. The analysis was performed by using a wavelength range from 4000 to $400 \mathrm{~cm}^{-1}$ in absorbance mode with a resolution of $4 \mathrm{~cm}^{-1}$.

Gel Permeation Chromatography (GPC) was carried out by using a Polymer Laboratories chromatograph; the solvent passing through the column was tetrahydrofuran (THF). After extraction in chloroform and evaporation of the solvent, the residues were dissolved in THF and injected into the column for the analysis. A calibration curve was obtained by using 5 standards of polystyrene as reference samples: results obtained from unknown samples were then compared in terms of retention times (and molecular weights) with the standard values.

A Laser Ionised Mass Analyser (LIMA) was used in order to identify the ions generated from the extracts after ionisation with a laser. This technique can analyse samples both in reflection and transmission under ultra-high vacuum conditions. Samples were loaded into the main chamber after passing through some induction chambers. A He: Ne spotting laser gave a very intense pulse of light that was transmitted to an optical system and focused on the site chosen for the analysis. The pulse of energy evaporated and ionised a micro volume of the sample. The resultant anions and cations were then accelerated and focused into the time-of-flight mass analyser. The ions travelled along the drift tube and were separated according to their masses; they were then detected by an electron multiplier and recorded with a transient recorder: spectra were acquired in less than 100 microseconds. 
FTIR, LIMA experiments and optical microscopy investigations were also carried out on the three antioxidants present in the material (a phenolic antioxidant and two phosphites). Solid particles were mixed with powdered $\mathrm{KBr}$ and pressed in order to obtain discs for the FTIR analysis, while solutions of antioxidants in chloroform were prepared in order to carry out LIMA experiments.

\section{Results}

Analysis of water aged samples

The set of ageing experiments suggested by the ECHIP software is shown in Table 1; ageing temperatures ranged from 90 to $190^{\circ} \mathrm{C}$ while ageing times ranged from $2 \mathrm{~h}$ to $500 \mathrm{~h}$; some trials were repeated for consistency. Comparing the FTIR spectra of the samples before and after ageing in water at $190^{\circ} \mathrm{C}$ for $251 \mathrm{~h}$ (figs 1 and 2), significant changes appear in the region where the carbonyl group absorbs (about $1700 \mathrm{~cm}^{-1}$ ). The carbonyl ratio was calculated as described previously [11], as the ratio between the area of the carbonyl peak and the area of the double peak at about $2920 \mathrm{~cm}^{-1}$ and $2850 \mathrm{~cm}^{-1}$ attributed respectively to the asymmetrical and symmetrical stretching of $\mathrm{CH}_{2}$ group, and used as a reference peak.

Table 1 shows that carbonyl ratio is very low up to ageing conditions of $190^{\circ} \mathrm{C}$ and $100 \mathrm{~h}$, at which it increases to a value of about 0.2 ; at the same ageing conditions, percentage crystallinity decreases from about $68 \%$ to a value of about $60 \%$. On increasing the ageing time at $190^{\circ} \mathrm{C}$ up to $500 \mathrm{~h}$, carbonyl ratio increases to about 0.65 and percentage crystallinity decreases to about $45 \%$. Fig. 3 shows the DSC trace obtained for a sample aged in water at $190^{\circ} \mathrm{C}$ for $251 \mathrm{~h}$ : percentage crystallinity decreases to about $45 \%$, melting and crystallization temperatures also show lower values compared with the results obtained for the unaged samples (before ageing $\mathrm{T}_{\mathrm{m}}=130^{\circ} \mathrm{C}$ and $\left.\mathrm{T}_{\mathrm{c}}=112^{\circ} \mathrm{C}\right)$.

Fig.4a shows that for long ageing times (500h), carbonyl ratio has a constant value of about 0.02 up to $155^{\circ} \mathrm{C}$ and then reaches a value of about 0.66 at ageing temperature of $190^{\circ} \mathrm{C}$. Fig. $4 \mathrm{~b}$ 
shows how carbonyl ratio increases with ageing time at $190^{\circ} \mathrm{C}$ : after $2 \mathrm{~h}$ ageing at this temperature, it has a value of 0.0015 , which increases up to 0.66 after $500 \mathrm{~h}$. Fig. 5 a shows that at $190^{\circ} \mathrm{C}$ percentage crystallinity decreases from a value of about $68 \%$ after $2 \mathrm{~h}$ ageing, to a value of about $45 \%$ after $500 \mathrm{~h}$ ageing at this temperature.

Finally, fig.5b shows the variation of percentage crystallinity with ageing temperature for long ageing times $(500 \mathrm{~h})$. A value of $65 \%$ is obtained for samples aged at $90^{\circ} \mathrm{C}$, and then crystallinity increases up to a maximum value of $77 \%$ at about $120^{\circ} \mathrm{C}$; on increasing the ageing temperature up to $190^{\circ} \mathrm{C}$, percentage crystallinity decreases to $45 \%$.

Fig. 6a shows the tensile data obtained for the samples aged in water at $157^{\circ} \mathrm{C}$ for $168 \mathrm{~h}$ : the material has a ductile behaviour, a yield strength of $22 \mathrm{MPa}$ and an elongation at break of about $550 \%$. Fig. $6 \mathrm{~b}$ shows the tensile data obtained for the samples aged at $190^{\circ} \mathrm{C}$ for $500 \mathrm{~h}$ : the material has a brittle behaviour, the yield strength decreases from about $22 \mathrm{MPa}$ to a value of 14 $\mathrm{MPa}$ and the elongation at break decreases to a value of $58 \%$.

A partial cubic model was chosen in order to fit the experimental results by using the ECHIP software: it predicted the ageing conditions (ageing times and temperatures) at which the outputs of the model (carbonyl ratio, percentage crystallinity and yield strength) reach extreme values. Fig. 7 a shows that a minimum value of $38 \%$ for percentage crystallinity is predicted for ageing at $190^{\circ} \mathrm{C}$ for $251 \mathrm{~h}$. Fig. $7 \mathrm{~b}$ shows a maximum value of 0.661 for carbonyl ratio, obtained for samples aged at $190^{\circ} \mathrm{C}$ for $437 \mathrm{~h}$.

Compared with the microstructures shown for air aged samples [11], water aged samples seem to be less degraded and some needle-like structures can be observed at the edges of the samples as shown in fig.8a. Fig.8b shows that crystals of phenolic antioxidant, recrystallized after melting, have a needle-like structure, very similar to the microstructure observed for water aged samples. 


\section{Analysis of extracts in chloroform}

The FTIR spectrum of the extract from a sample aged in water at $150^{\circ} \mathrm{C}$ for $30 \mathrm{~h}$ (fig.9) and the main FTIR findings summarized in table 2 show that in all the extracts there are very intense peaks at frequencies where groups containing silicone absorb $\left(800-1200 \mathrm{~cm}^{-1}\right)$, the siloxane bonds which could be due to the condensation of free silane molecules. No significant carbonyl absorption is observed for any of the samples analysed.

Fig. 10 is the LIMA spectrum of the anions generated by the extract from a sample aged in water at $150^{\circ} \mathrm{C}$ for $30 \mathrm{~h}$, while table 3 summarizes the main findings obtained by LIMA experiments carried out on all the extracts of water aged samples. It shows that all the extracts produce the anion $\mathrm{CN}$, which is an impurity due to some contamination in the samples; the anion Si comes from the silica wafer, the support for the samples used for the analysis. Extracts E1, E2 and E3 generate the anion $\mathrm{CHCO}(\mathrm{m} / \mathrm{z} 41)$; samples E2 and E3 produce also the anions $\mathrm{PO}_{2}(\mathrm{~m} / \mathrm{z}$ 63) and $\mathrm{PO}_{3}(\mathrm{~m} / \mathrm{z} 79)$, probably due to the presence of phosphite antioxidants. All the samples produce cations containing $\mathrm{Si}$, in particular groups of $\mathrm{m} / \mathrm{z} 73$ and 147 , attributed to the groups $\mathrm{SiC}_{3} \mathrm{H}_{9}$ and $\mathrm{C}_{5} \mathrm{H}_{15} \mathrm{OSi}_{2}$ respectively.

Table 3 is a summary of the main findings obtained by the experimental analysis of the extracts from water aged samples (FTIR, GPC and LIMA); the same experimental techniques were applied to the three antioxidants present in the material. Table 2 summarizes the main findings obtained for the three antioxidants (a phenolic one and two phosphites).

\section{Discussion}

Solvent extraction in boiling xylene was carried out on some samples aged in water at $190^{\circ} \mathrm{C}$ for different times; they showed similar values of gel content (73-77\%) to the ones obtained before ageing, therefore ageing in water does not seem to lead to significant C-C crosslinking. In the region of the spectrum where groups containing silicon absorb (figs 1 and 2), several siloxane structures form in water at high temperatures. There are possibly cyclic siloxanes 
absorbing at different frequencies between 1020 and $1090 \mathrm{~cm}^{-1}$ [13-15]. The water condensation reaction of silanol groups to siloxane is reversible; in presence of water at elevated temperatures, the dissolution of siloxane bonds to produce silanol groups is favoured [16]. Alcoholysis and hydrolysis of siloxane bonds (equation (1)) provide a means for bond breakage and reformation allowing continual restructuring of the growing polymers and forming cyclic structures [16]. The rate of hydrolysis of siloxane bonds exhibits strong $\mathrm{pH}$ dependence and increases by over three orders of magnitude in aqueous solution between about $\mathrm{pH} 3$ and 8 .

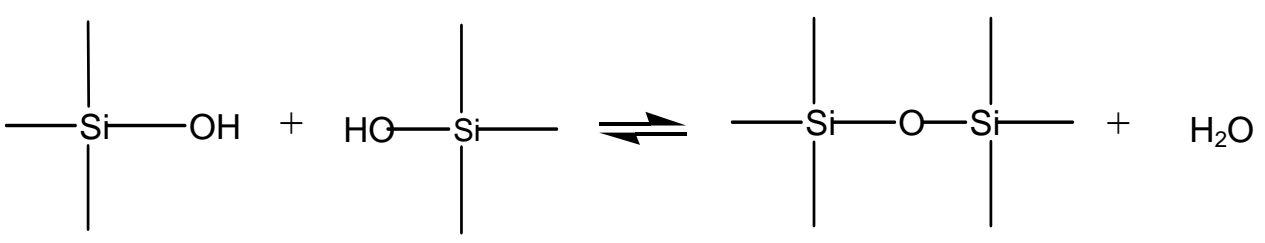

No oxidation seems to occur in the samples aged at low temperatures (up to $157^{\circ} \mathrm{C}$ ) for different times, as the carbonyl peak is barely visible and is attributed to the carbonyl present in the phenolic antioxidant. On increasing the ageing temperature up to $190^{\circ} \mathrm{C}$ for long ageing times, significant changes can be observed in the region of the spectrum where groups containing carbonyl absorb; three different peaks are observed, attributed respectively to ketone, ester and acid or anhydride, according to different stages of oxidation. This could be attributed to a mechanism of hydrolytic oxidation, occurring after ageing in water at $190^{\circ} \mathrm{C}$ for long times in agreement with some findings by Allen et al [17], who carried out a study on oxidation processes in blue polyolefin water pipes. They measured a consistent decrease in the OIT throughout the pipe wall and an increase of the carbonyl index, attributed to an unusual hydrolytic oxidation and extraction of the carbonylic oxidation products only at the outer pipe surface. In this work, along with some other studies carried out by Dorner et al $[18,19]$, the deterioration of the polymer/stabilizer systems as a result of stabilizer migration and consumption (antioxidant leaching) in water at elevated temperatures was observed. Although a 
clear mechanism to explain the hydrolytic oxidation occurring in water at high temperatures has not been found yet, one possible explanation is proposed as follows (equations (2) and (3)), based on the electrophilic hydrolysis of terminal double bonds present in polyethylene, a reaction that is promoted by protons formed because of water dissociation at elevated temperatures [20]:<smiles>CC/C=C/[CH+]CCC[CH+]CO</smiles><smiles>CCC(C)C(O)[CH+]CCCCCCC=O</smiles>

The presence of high concentrations of carbonyl groups in samples aged in water at elevated temperatures can therefore be attributed to both hydrolytic oxidation occurring in these conditions and to extraction of the phenolic antioxidant, which migrates to the surface of the sample, as observed by optical microscopy investigations and by chemical analysis carried out on the extracts in chloroform of samples aged in water (FTIR, GPC and LIMA). This is confirmed by the presence of sharp peaks in the frequency range $3620-3645 \mathrm{~cm}^{-1}$ in the FTIR spectra of water aged samples, attributed to $\mathrm{OH}$ groups [21], which derive both from the migration of the phenolic antioxidant and from the hydrolytic oxidation reactions proposed above.

DSC analysis on water aged samples showed that percentage crystallinity, melting temperature and crystallization temperature start to decrease only after ageing the samples in water at $190^{\circ} \mathrm{C}$ for long ageing times (fig.3), according to the mechanism of hydrolytic oxidation suggested 
above. Table 1 and figs 4 and 5 show the variations of the outputs of the model with the ageing conditions. Initially carbonyl ratio has a constant small value of about 0.03 and then it increases significantly to 0.66 for samples aged at $190^{\circ} \mathrm{C}$ for $500 \mathrm{~h}$. Percentage crystallinity increases up to $120^{\circ} \mathrm{C}$ because of annealing in water and then it starts to decrease, reaching a value of $45 \%$ after ageing at $190^{\circ} \mathrm{C}$ for $500 \mathrm{~h}$, due to oxidation which disrupts structural order; the yield strength decreases with ageing temperature to a value of about $14 \mathrm{MPa}$ for samples aged at $190^{\circ} \mathrm{C}$ for $500 \mathrm{~h}$, as polymer degradation occurs.

Mechanical properties of the material after ageing in water are significantly affected by structural changes occurring during ageing, which correspond to changes of the shape of tensile curves with different ageing conditions. Fig. 11a shows that at the ageing temperature of $90^{\circ} \mathrm{C}$ from $168 \mathrm{~h}$ the elongation at break increases with the ageing time, because in these conditions the hydrolysis of siloxane bonds in water is predominant, therefore the material can be stretched more before failure. Fig. $11 \mathrm{~b}$ shows the variation of elongation at break with ageing time at $190^{\circ} \mathrm{C}$; up to $100 \mathrm{~h}$ ageing time at this temperature, the elongation at break is constant at a value of about $350 \%$, then on increasing the ageing time up to $500 \mathrm{~h}$, it decreases significantly (about $50 \%$ ), because in these conditions the effect of polymer degradation is predominant on the hydrolysis of siloxane bonds.

Table 4 shows the variation of carbonyl ratio with elongation at break for samples aged in water for different times at 90 and $190^{\circ} \mathrm{C}$ respectively. At $90^{\circ} \mathrm{C}$ carbonyl ratio is constant at very low values $(\leq 0.02)$ as the polymer is not significantly degraded and on ageing from $168 \mathrm{~h}$ onwards the elongation at break increases with the ageing time, since the effect of siloxane bond breakage is predominant. At $190^{\circ} \mathrm{C}$ carbonyl ratio shows very high values (about 0.65 ) for samples aged for long times, which have very low elongations (about 50\%) since in these conditions the effect of polymer degradation prevails; samples aged at $190^{\circ} \mathrm{C}$ for short times (up to $100 \mathrm{~h}$ ) show high elongation at break and very low values of carbonyl ratio, as siloxane crosslinks hydrolysis is predominant. 
When the microstructures of samples aged in water at $190^{\circ} \mathrm{C}$ for $500 \mathrm{~h}$ and the microstructure of recrystallized phenolic antioxidant are compared (figs $8 \mathrm{a}$ and $8 \mathrm{~b}$ ), they both show some needlelike structures; this suggests that in the water aged sample, the antioxidant was washed away by water, (i.e. a physical mechanism of consumption). Tables 2 and 3 summarize the main findings obtained by performing FTIR, GPC and LIMA experiments on the antioxidants and on the extracts of water aged samples respectively. Comparing the molecular weights of antioxidants supplied with the ones of the extracts of water aged samples obtained by GPC tests and comparing the sets of anions generated after ionisation in LIMA experiments, it seems that in the unaged samples just the phenolic antioxidant is extracted. Ageing in water at $150^{\circ} \mathrm{C}$ up to 85h, also allows the phosphite antioxidants in the sample to be extracted; it appeared that antioxidants had been washed away by water as there is no evidence of any antioxidant in the extract of the sample aged at $150^{\circ} \mathrm{C}$ for $161 \mathrm{~h}$, as discussed previously. All the extracts show in their cation spectra some groups containing silicone: they could be attributed to some free silane molecules which do not graft to the polymer chains and condense generating siloxane bonds. Figs $12 \mathrm{a}$ and $12 \mathrm{~b}$ show a comparison of the air and water ageing results obtained, in terms of variations of carbonyl ratio and percentage crystallinity with the ageing conditions.

Fig. 12a shows that up to $155^{\circ} \mathrm{C}$ carbonyl ratio has very similar values for samples aged in air and water for $500 \mathrm{~h}$; for higher ageing temperatures, it increases more significantly during water ageing, reaching a value of 0.66 at $190^{\circ} \mathrm{C}$, which is much higher than the value calculated for air aged samples at $220^{\circ} \mathrm{C}(0.14)$; this suggests that the degradation processes in air and in water occur according to two different mechanisms, as degradation in air is caused by oxygen diffusion favoured at elevated temperatures, while degradation in water is caused by hydrolytic oxidation and antioxidant extraction. Fig.12b shows that both samples aged in air and water underwent annealing for ageing temperatures up the melting point of the material; on increasing the ageing temperatures, in both cases percentage crystallinity decreases as degradation occurs. 


\section{Conclusions}

Oxidation does not seems to occur in the samples aged in water at low temperatures (up to about $155^{\circ} \mathrm{C}$ ) for different times, as the carbonyl peak is weak and is attributed to the carbonyl present in the phenolic antioxidant. On increasing the ageing temperature up to $190^{\circ} \mathrm{C}$ for long ageing times, a mechanism of hydrolytic oxidation occurs, along with the deterioration of the polymer/stabilizer system as a result of stabilizer migration and consumption (antioxidant leaching). Mechanical properties of the material after ageing in water are significantly affected by structural changes occurring during ageing, which correspond to changes of the shape of tensile curves with different ageing conditions. When the microstructures of samples aged in water at $190^{\circ} \mathrm{C}$ for $500 \mathrm{~h}$ are compared with the microstructure of the phenolic antioxidant recrystallized after melting, they both show some needle-like structures; this suggests that in the water aged sample, the antioxidant was washed away by water. This hypothesis is confirmed by the experimental results obtained by carrying out several chemical investigations (FTIR, GPC and LIMA) on extracts of water aged samples and on solutions of the antioxidants in chloroform.

\section{Acknowledgements}

The authors would like to thank Wavin Plastics Ltd for the support provided to this work. 


\section{References}

1. S. Al-Malaika: 'Reactive modifiers for polymers'; 1997, London, Blackie Academic \& Professional.

2. R. Gachter, H. Muller: 'Plastics Additives Handbook', $2^{\text {nd }}$ Edition, 1987, Hanser Publishers.

3. U.W. Gedde, J.Viebke, H. Leijstrom, M. Ifwarson: Polymer Engineering and Science, 1994, 34(24), 1773-1787.

4. U.W. Gedde, M. Ifwarson: Polymer Engineering and Science, 1990, 30(4), 202-210.

5. K. Karlsson, G.D. Smith, U.W. Gedde: Polymer Engineering and Science, 1992, 32(10), 649-657.

6. J. Viebke, U.W. Gedde: Polymer Engineering and Science, 1998, 38, 1244.

7. M. Tsunaga, S. Matsunami, M. Sato, K. Nakata: "Plastics Pipes X" Conference Proceedings, Gothenburg, Sweden, 1998.

8. J. Viebke, M. Hedenqvist, U.W. Gedde: Polymer Engineering and Science, 1996, 36(4), 458.

9. J. Viebke, E. Elble, M. Ifwarson, U.W. Gedde: Polymer Engineering and Science, 1994, 34(17), 1354-1361.

10. A. Caswell: Technical Report, Wavin Plastics Ltd, UK, 2001.

11. L.Amato, M. Gilbert, A. Caswell: Plastics, Rubber \& Composites: Macromolecular Engineering, March 2005.

12. Micropol Ltd: Technical Report, UK, 1998.

13. A. Lee Smith: Spectrochimica Acta, 1960, 16, 87-105.

14. A.L. Smith: 'Analysis of Silicones', Vol. 41, 247, 1974, John Wiley \& Sons, US.

15. R.M. Silverstein, G.C. Bassler, T.C. Morrill: 'Spectrometric Identification of Organic Compounds', $5^{\text {th }}$ edn, 1991, John Wiley \& Sons, Inc, US.

16. C.J. Brinker, G.W. Scherer: 'Sol'Gel Science: the physics and chemistry of sol-gel processing'; 1990, US, Harcourt Brace Jovanovich Publishers.

17. N.S. Allen, G.P. Marshall, C. Vasiliou, L.M. Moore, J.L. Kotecha: Polymer Degradation and Stability, 1988, 20, 315-324.

18. G. Dorner, R.W. Lang: Polymer Degradation and Stability, 1998, 62, 421-430.

19. G. Dorner, R.W. Lang: Polymer Degradation and Stability, 1998, 62, 431-440.

20. J. March: 'Advanced Organic Chemistry'; $4^{\text {th }}$ ed., 1992, US, John Wiley \& Sons.

21. L. Bellamy: 'Advances in Infrared Group Frequencies', 1968, The Chaucer Press Ltd, UK. 


\section{Figure captions}

Fig.1 FTIR spectrum of a sample before ageing

Fig.2 FTIR spectrum of a sample aged in water at $190^{\circ} \mathrm{C}-251 \mathrm{~h}\left(2000-800 \mathrm{~cm}^{-1}\right)$

Fig.3 DSC analysis for a sample aged in water at $190^{\circ} \mathrm{C}$ for $251 \mathrm{~h}$

Fig.4a Variation of carbonyl ratio with ageing $\mathrm{T}$ (ageing time 500h)

Fig.4b Variation of carbonyl ratio with ageing time (ageing temperature $190^{\circ} \mathrm{C}$ )

Fig.5a Variation of \% crystallinity with ageing time (ageing temperature $190^{\circ} \mathrm{C}$ )

Fig.5b Variation of \% crystallinity with ageing $\mathrm{T}$ (ageing time $500 \mathrm{~h}$ )

Fig.6a Tensile data for samples aged in water at $157^{\circ} \mathrm{C}$ for $168 \mathrm{~h}$

Fig.6b Tensile data for samples aged in water at $190^{\circ} \mathrm{C}$ for $500 \mathrm{~h}$

Fig.7a ECHIP analysis of water ageing results: minimum \% crystallinity

Fig.7b ECHIP analysis of water ageing results: maximum $\mathrm{C}=\mathrm{O}$ ratio

Fig.8a Microstructures of sample aged in water at $190^{\circ} \mathrm{C}$ for $500 \mathrm{~h}$

Fig.8b Microstructure of phenolic antioxidant after melting

Fig.9 FTIR spectrum of extract from sample aged in water at $150^{\circ} \mathrm{C}$ for $30 \mathrm{~h}$

Fig.10 LIMA spectrum of anions generated by extract from sample aged at $150^{\circ} \mathrm{C}$ for $30 \mathrm{~h}$

Fig.11a Variation of elongation at break with ageing time at $90^{\circ} \mathrm{C}$

Fig.11b Variation of elongation at break with ageing time at $190^{\circ} \mathrm{C}$

Fig.12a Variation of $\mathrm{C}=\mathrm{O}$ ratio with ageing temperature during air and water ageing for $500 \mathrm{~h}$

Fig.12b Variation of crystallinity with ageing temperature during air and water ageing for $500 \mathrm{~h}$ 
Table 1 Set of experimental trials suggested by the ECHIP software

\begin{tabular}{|c|c|c|c|c|c|}
\hline Trials & Ageing time (h) & Ageing T $\left({ }^{\circ} \mathbf{C}\right)$ & $\boldsymbol{C}=\boldsymbol{O}$ ratio & \% Cryst. & Yield str. (MPa) \\
\hline 1 & 2 & 190.0 & 0.001 & 69.0 & 20.8 \\
\hline 2 & 2 & 190.0 & 0.002 & 64.0 & 21.2 \\
\hline 3 & 2 & 140.0 & 0.011 & 64.8 & 20.5 \\
\hline 4 & 2 & 140.0 & 0.010 & 68.0 & 21.0 \\
\hline 5 & 100 & 190.0 & 0.190 & 59.2 & 21.7 \\
\hline 6 & 100 & 190.0 & 0.210 & 60.3 & 22.0 \\
\hline 7 & 251 & 190.0 & 0.690 & 50.1 & 12.1 \\
\hline 8 & 251 & 190.0 & 0.450 & 42.5 & 13.5 \\
\hline 9 & 500 & 190.0 & 0.670 & 43.0 & 14.5 \\
\hline 10 & 500 & 190.0 & 0.630 & 52.0 & 14.2 \\
\hline 11 & 500 & 90.0 & 0.026 & 68.0 & 22.7 \\
\hline 12 & 500 & 90.0 & 0.017 & 62.3 & 23.0 \\
\hline 13 & 2 & 90.0 & 0.005 & 72.0 & 21.0 \\
\hline 14 & 334 & 90.0 & 0.016 & 66.0 & 23.4 \\
\hline 15 & 168 & 90.0 & 0.002 & 73.4 & 20.0 \\
\hline 16 & 500 & 123.3 & 0.002 & 76.0 & 21.5 \\
\hline 17 & 500 & 157.6 & 0.037 & 62.3 & 21.3 \\
\hline 18 & 168 & 157.6 & 0.042 & 64.8 & 22.0 \\
\hline
\end{tabular}


Table 2 Summary of experimental results obtained for extracts from water aged samples

\begin{tabular}{|c|c|c|c|c|c|}
\hline Samples & Details & FTIR & GPC & $\begin{array}{c}\text { LIMA } \\
\text { (anions) }\end{array}$ & $\begin{array}{c}\text { LIMA } \\
\text { (cations) }\end{array}$ \\
\hline E1 & $\begin{array}{l}\text { Unaged } \\
\text { sample }\end{array}$ & $\begin{array}{c}\mathrm{H}_{2} \mathrm{O}, \mathrm{OH}, \\
\text { very low } \mathrm{C}=\mathrm{O}, \\
\text { Si-O-C bonds, } \\
\text { Si-O-Si bonds }\end{array}$ & $M=1060$ & $\begin{array}{c}\mathrm{CN}, \\
\mathrm{CHCO}, \\
\mathrm{CH}_{3} \mathrm{COO}\end{array}$ & $\begin{array}{c}\mathrm{Si}, \mathrm{SiOH}, \\
\mathrm{SiC}_{3} \mathrm{H}_{9}, \\
\mathrm{C}_{5} \mathrm{H}_{15} \mathrm{OSi}_{2}\end{array}$ \\
\hline E2 & $\begin{array}{c}\text { Aged } \\
150^{\circ} \mathrm{C}-3 \mathrm{~h}\end{array}$ & $\begin{array}{c}\mathrm{H}_{2} \mathrm{O}, \mathrm{OH}, \\
\text { low } \mathrm{C}=\mathrm{O}, \\
\text { Si-O-C bonds, } \\
\text { Si-O-Si bonds }\end{array}$ & $M=950$ & $\begin{array}{c}\mathrm{CN}, \\
\mathrm{CHCO}, \mathrm{Si}, \\
\mathrm{PO}_{2}, \mathrm{PO}_{3}, \\
\mathrm{C}_{6} \mathrm{H}_{5} \mathrm{O}\end{array}$ & $\begin{array}{c}\mathrm{Na}, \mathrm{Si}, \mathrm{SiOH}, \\
\mathrm{SiC}_{3} \mathrm{H}_{9} \\
\mathrm{C}_{5} \mathrm{H}_{15} \mathrm{OSi}_{2}\end{array}$ \\
\hline E3 & $\begin{array}{l}\text { Aged } \\
150^{\circ} \mathrm{C}- \\
85 \mathrm{~h}\end{array}$ & $\begin{array}{c}\mathrm{H}_{2} \mathrm{O}, \mathrm{OH}, \\
\text { low } \mathrm{C}=\mathrm{O}, \\
\text { Si-O-C bonds, } \\
\text { Si-O-Si bonds }\end{array}$ & $\mathrm{M}=920$ & $\begin{array}{c}\mathrm{CN}, \\
\mathrm{CHCO}, \\
\mathrm{Si}, \mathrm{PO}_{2}, \\
\mathrm{PO}_{3}\end{array}$ & $\begin{array}{l}\mathrm{Si}, \mathrm{SiOH}, \\
\mathrm{SiC}_{3} \mathrm{H}_{9}, \\
\mathrm{C}_{5} \mathrm{H}_{15} \mathrm{OSi}_{2}\end{array}$ \\
\hline E4 & $\begin{array}{l}\text { Aged } \\
150^{\circ} \mathrm{C}- \\
161 \mathrm{~h}\end{array}$ & $\begin{array}{c}\mathrm{H}_{2} \mathrm{O}, \mathrm{OH}, \\
\text { low } \mathrm{C}=\mathrm{O}, \\
\text { Si-O-C bonds, } \\
\text { Si-O-Si bonds }\end{array}$ & $M=1610$ & $\mathrm{CN}$ & $\begin{array}{c}\mathrm{SiC}_{3} \mathrm{H}_{9}, \\
\mathrm{C}_{5} \mathrm{H}_{15} \mathrm{OSi}_{2}\end{array}$ \\
\hline
\end{tabular}


Table 3 Summary of experimental results obtained for the antioxidants

\begin{tabular}{|c|c|c|c|c|c|}
\hline Samples & Details & FTIR & Molar mass & $\begin{array}{c}\text { LIMA } \\
\text { (anions) }\end{array}$ & $\begin{array}{c}\text { LIMA } \\
\text { (cations) }\end{array}$ \\
\hline \multirow{2}{*}{ Phenol. } & Phenol.antiox. & $\mathrm{H}_{2} \mathrm{O}, \mathrm{OH}$, high $\mathrm{C}=\mathrm{O}$ & $\mathrm{M}=1178$ & $\begin{array}{c}\mathrm{CHCO}, \\
\mathrm{CH}_{3} \mathrm{COO},\end{array}$ & $\mathrm{Na}$ \\
& & & & $\mathrm{C}_{6} \mathrm{H}_{5} \mathrm{O}$ & \\
\hline Phosph.1 & Phosph.antiox. & $\mathrm{H}_{2} \mathrm{O}, \mathrm{OH}$, & $\mathrm{M}=647$ & $\mathrm{PO}_{2}$, & $\mathrm{Na}$ \\
& & $\mathrm{P}-\mathrm{O}$ bonds & & $\mathrm{PO}_{3}$ & $\mathrm{Si}$ \\
\hline Phosph.2 & Phosph.antiox. & $\mathrm{H} \mathrm{H}_{2} \mathrm{O}, \mathrm{OH}$, & $\mathrm{M}=991$ & $\mathrm{PO}_{2}$, & $\mathrm{Na}$ \\
& & $\mathrm{P}-\mathrm{O}$ bonds & & $\mathrm{PO}_{3}$ & $\mathrm{Si}$ \\
\hline
\end{tabular}


Table 4 Variation of carbonyl ratio with elongation at break (ag. temp. 90 and $190^{\circ} \mathrm{C}$ )

\begin{tabular}{|c|c|c|c|}
\hline Ageing T ( $\left.{ }^{\circ} \mathbf{C}\right)$ & Ageing time (h) & Elong. at break (\%) & $\mathbf{C}=\mathbf{O}$ ratio \\
\hline 90 & 2 & 350 & 0.005 \\
\hline 90 & 168 & 163 & 0.002 \\
\hline 90 & 334 & 209 & 0.002 \\
\hline 90 & 500 & 237 & 0.02 \\
\hline 190 & 2 & 327 & 0.017 \\
\hline 190 & 100 & 350 & 0.02 \\
\hline 190 & 251 & 40 & 0.57 \\
\hline 190 & 500 & 58 & 0.65 \\
\hline
\end{tabular}




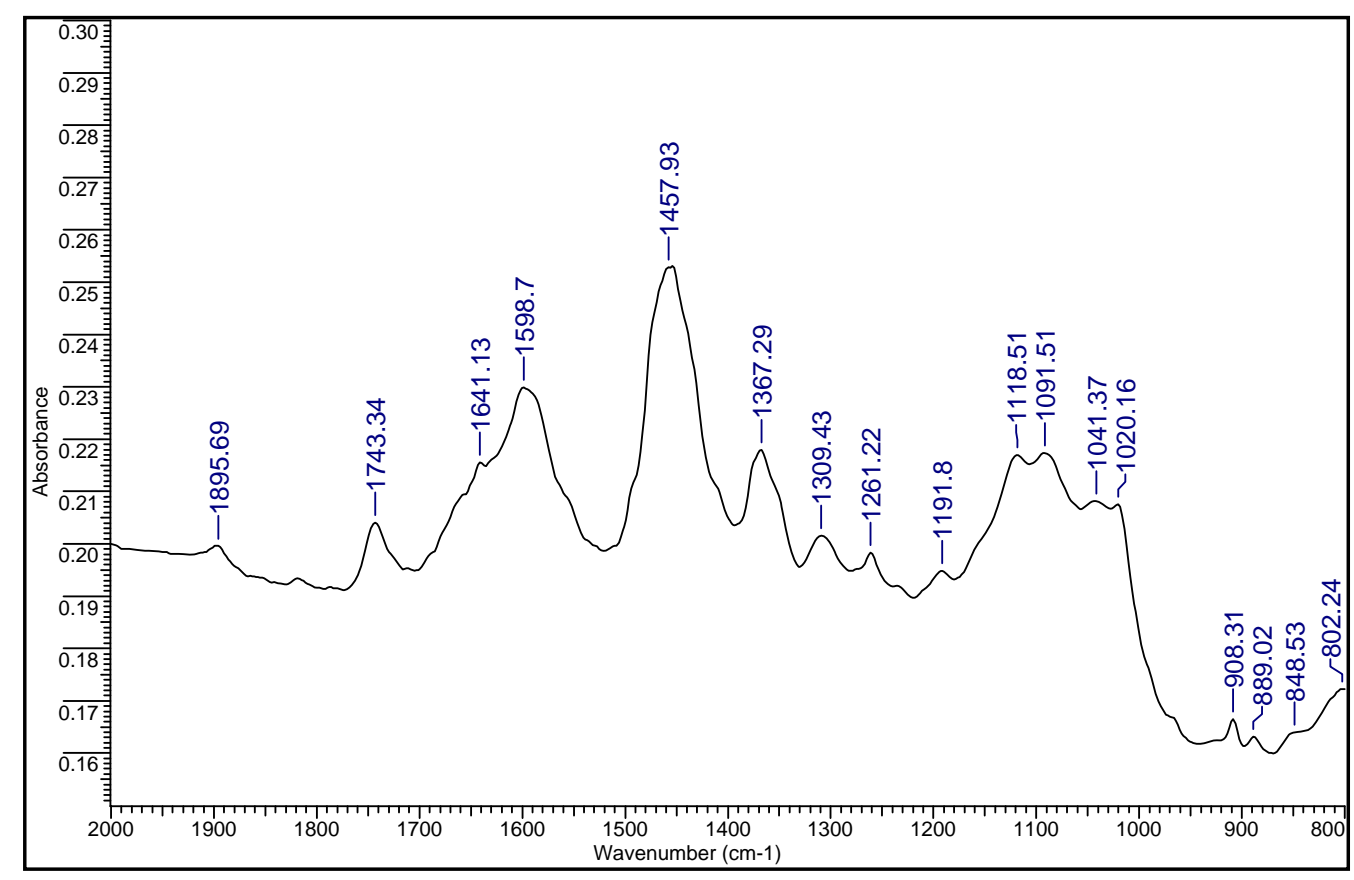

Fig.1

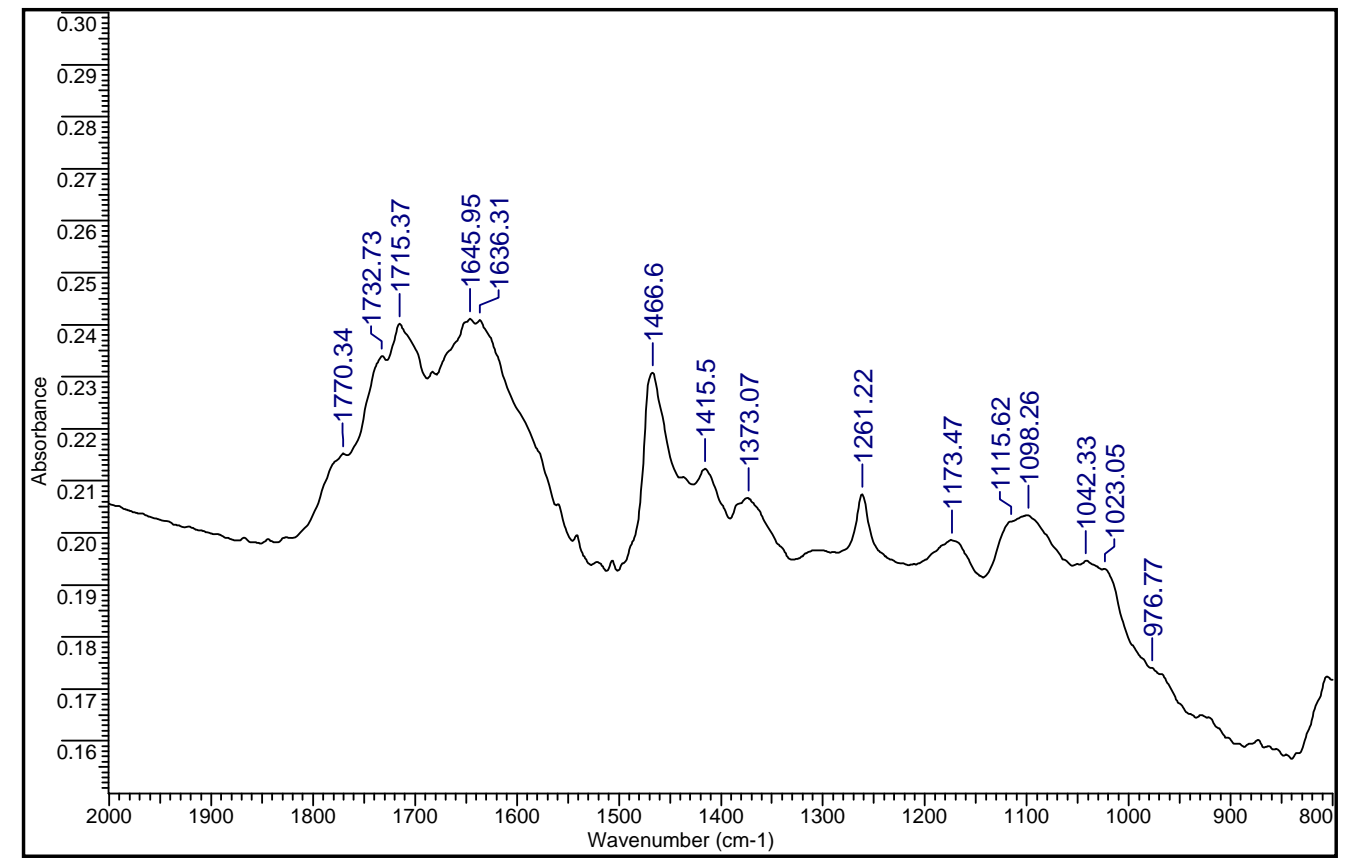

Fig.2 


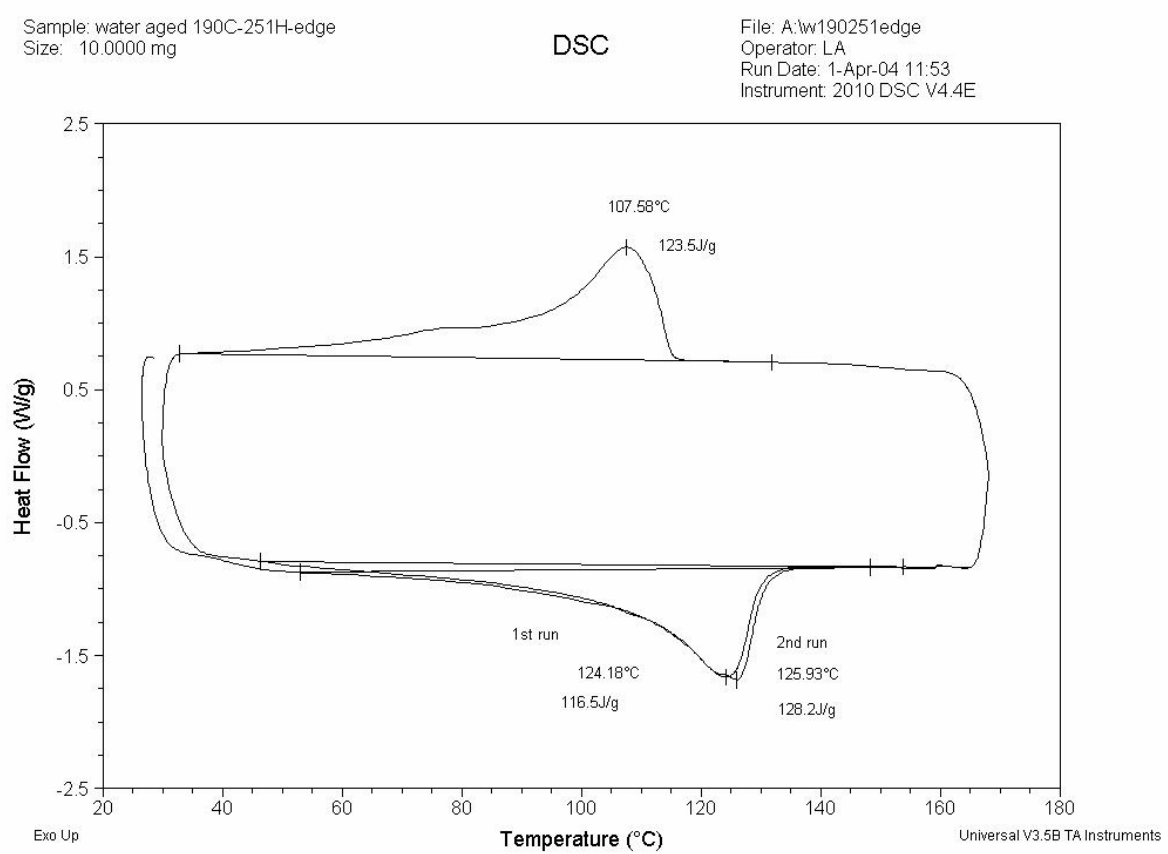

Fig.3 


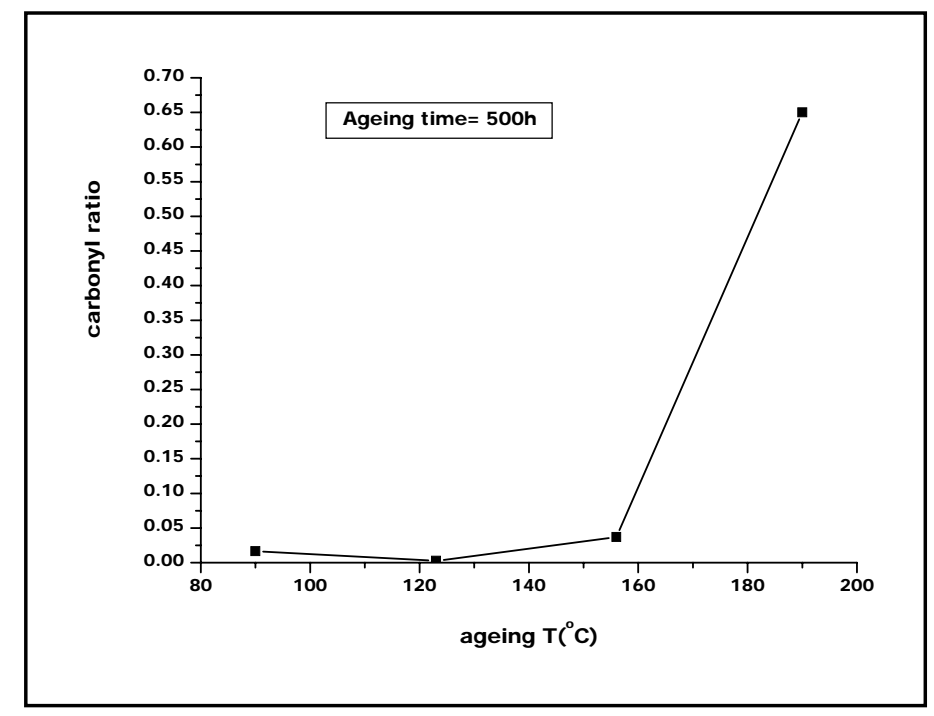

Fig.4a

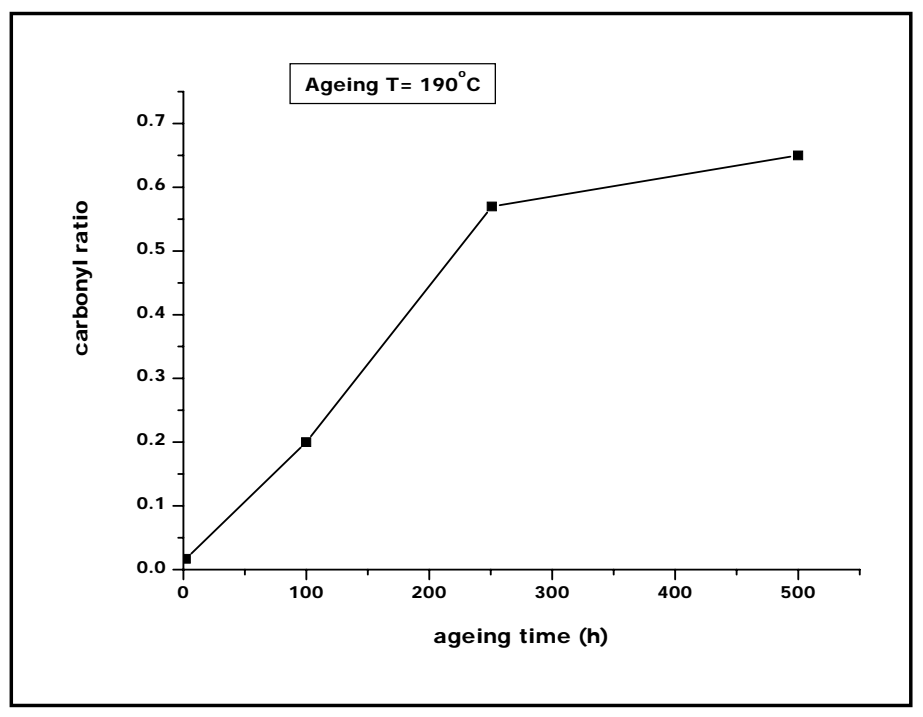

Fig. $4 b$ 


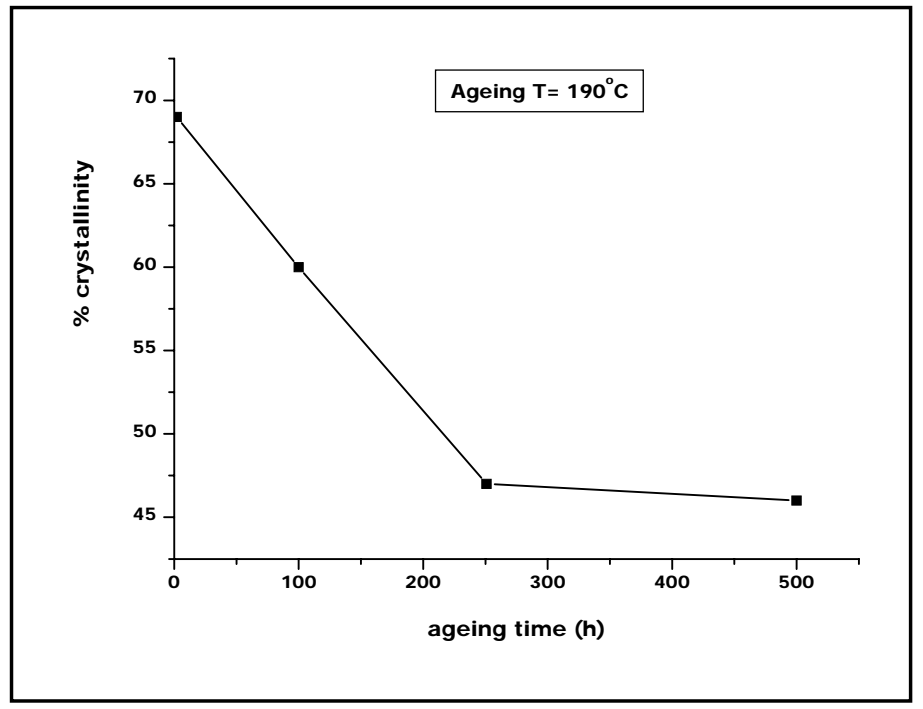

Fig. $5 a$

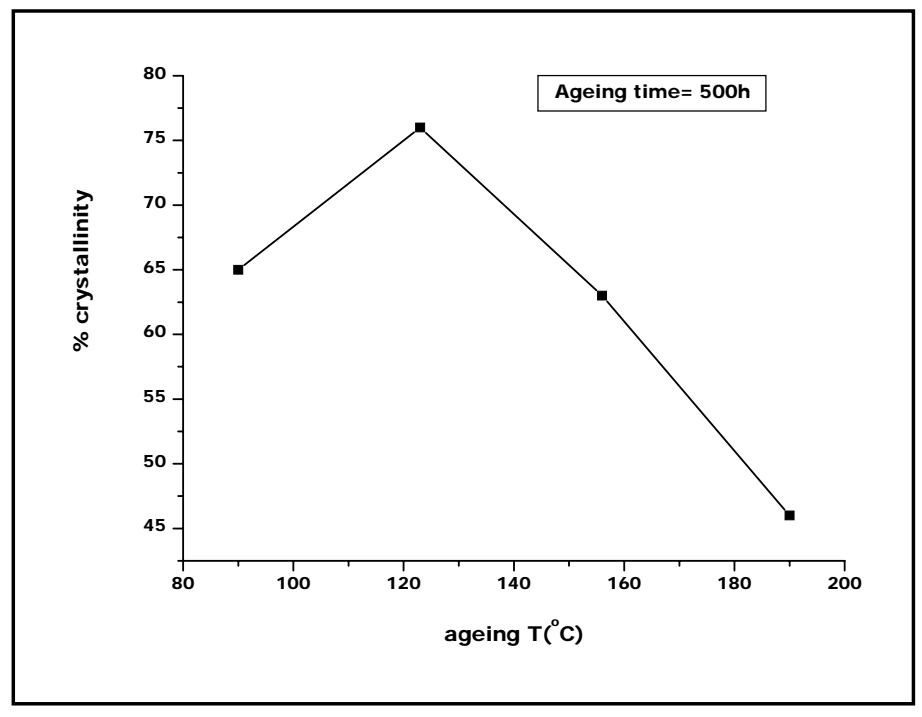

Fig. $5 b$ 


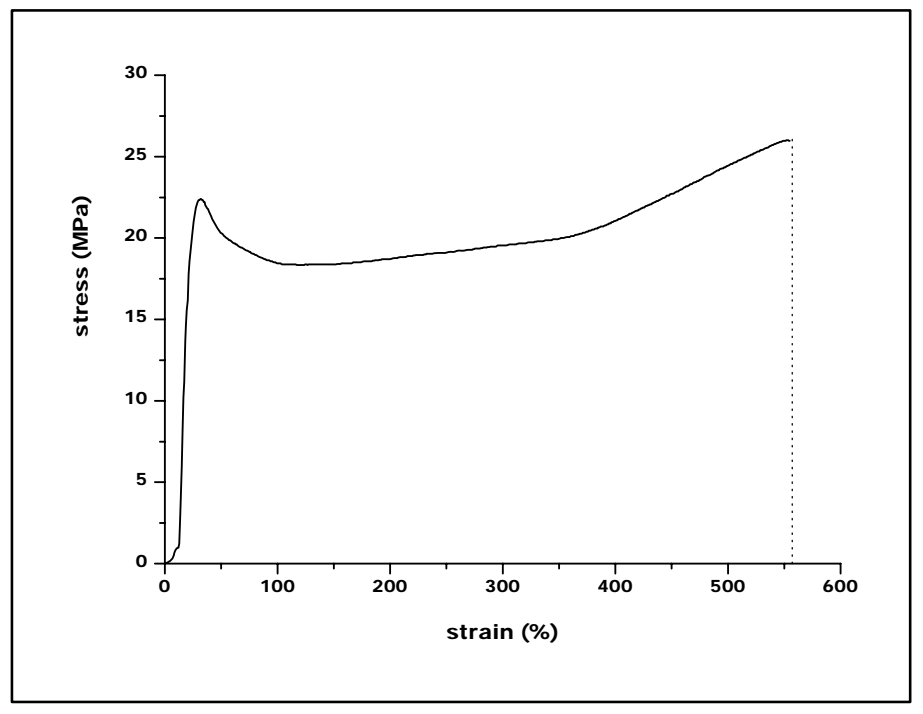

Fig. $6 a$

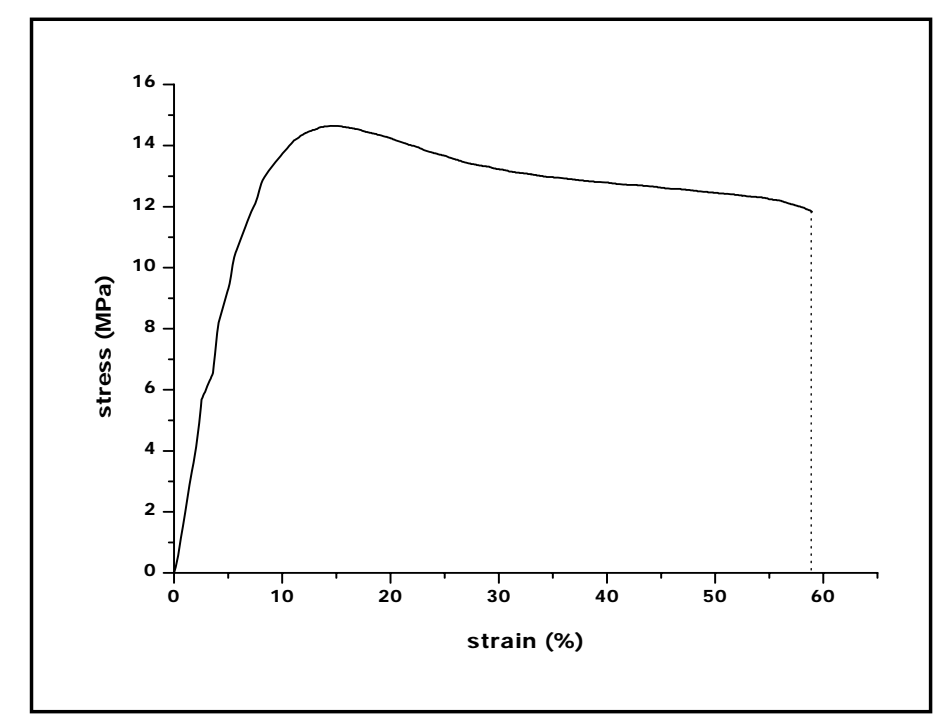

Fig. 6b 


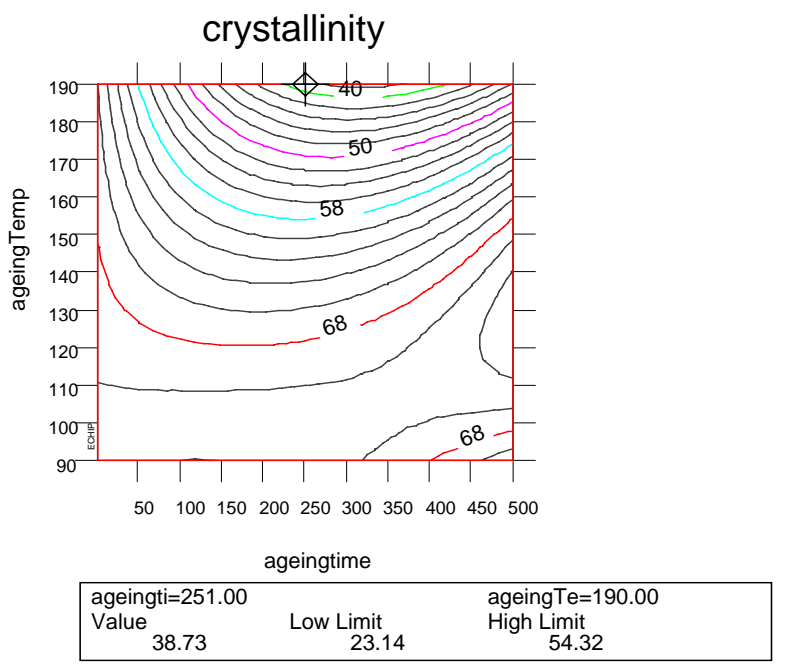

Fig. 7a

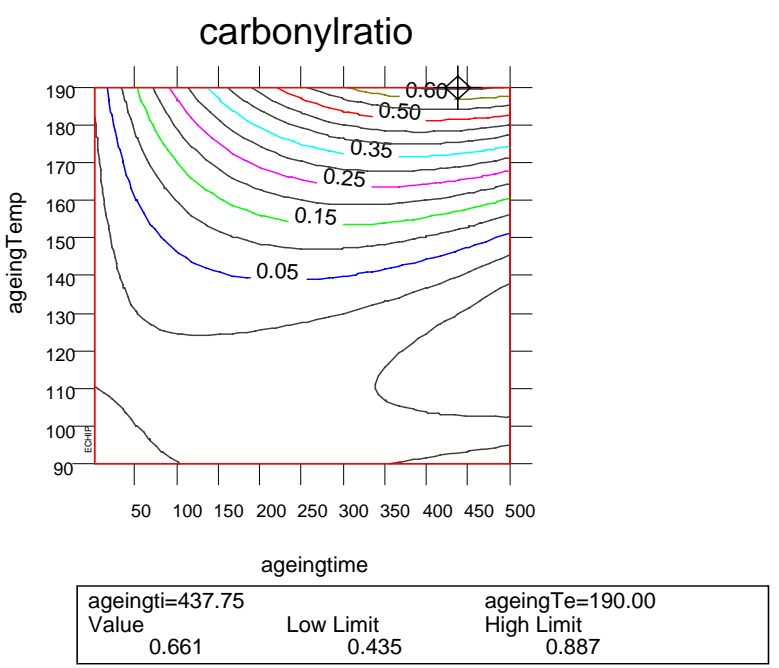

Fig. $7 b$ 


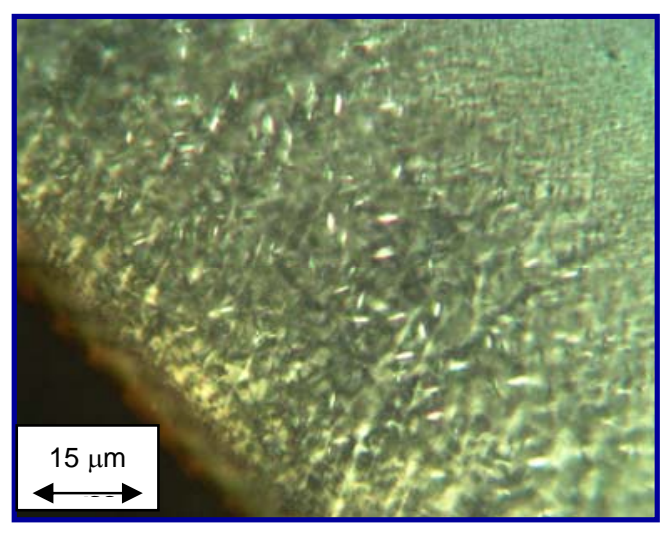

Fig. $8 a$

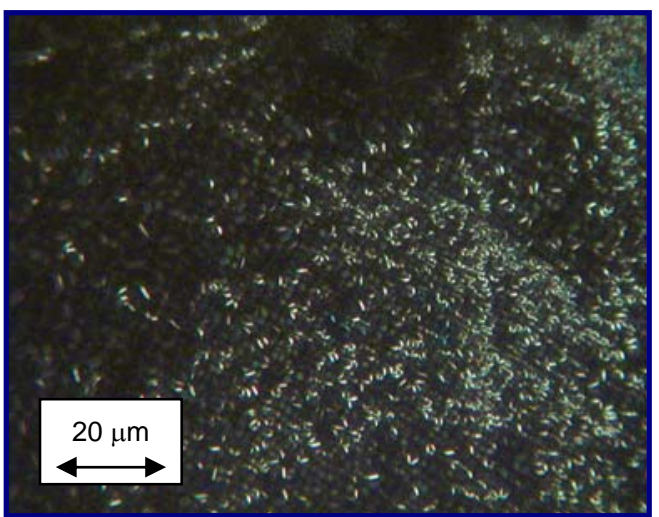

Fig. $8 b$ 


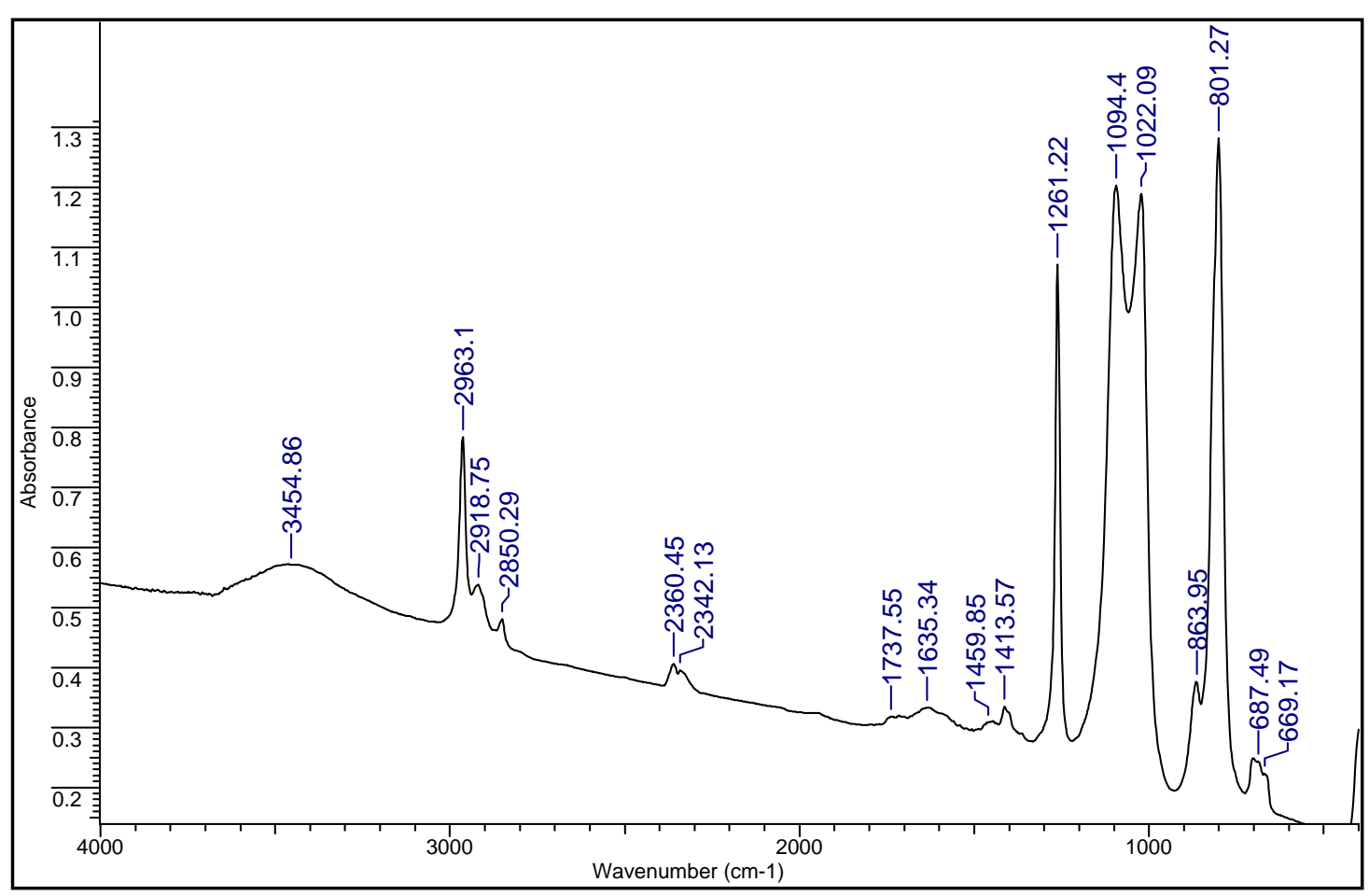

Fig. 9

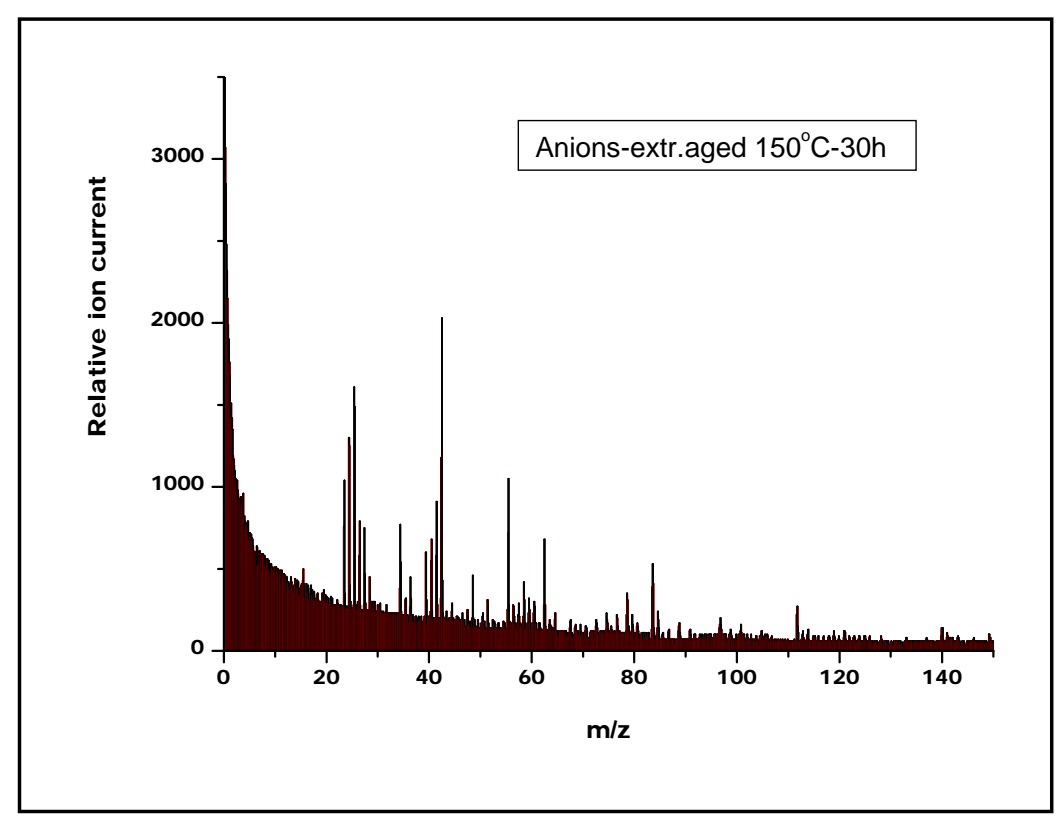

Fig.10 


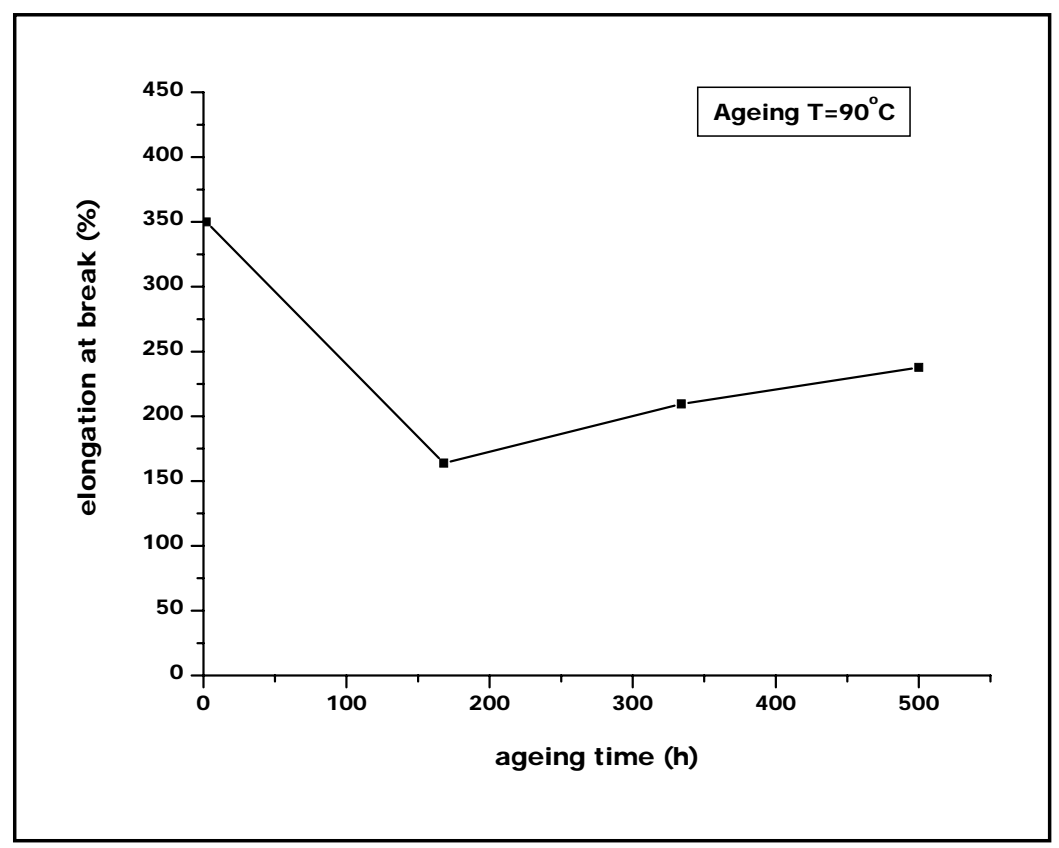

Fig.11a

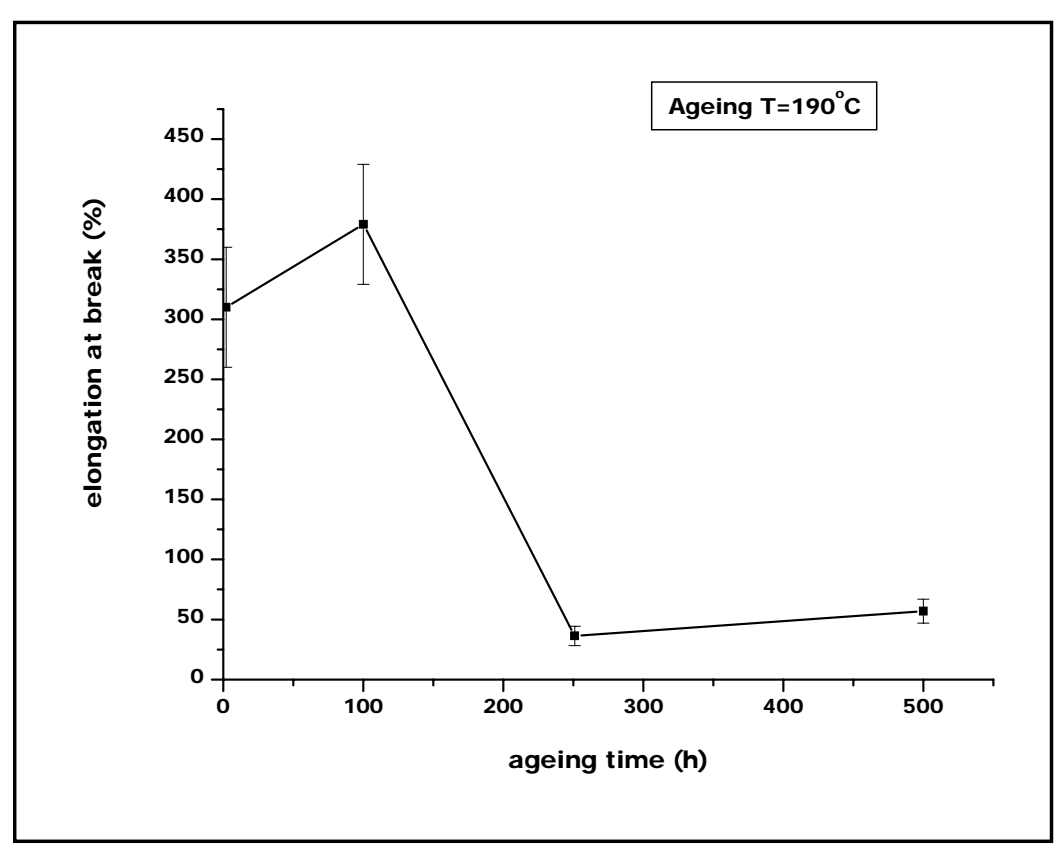

Fig.11b 


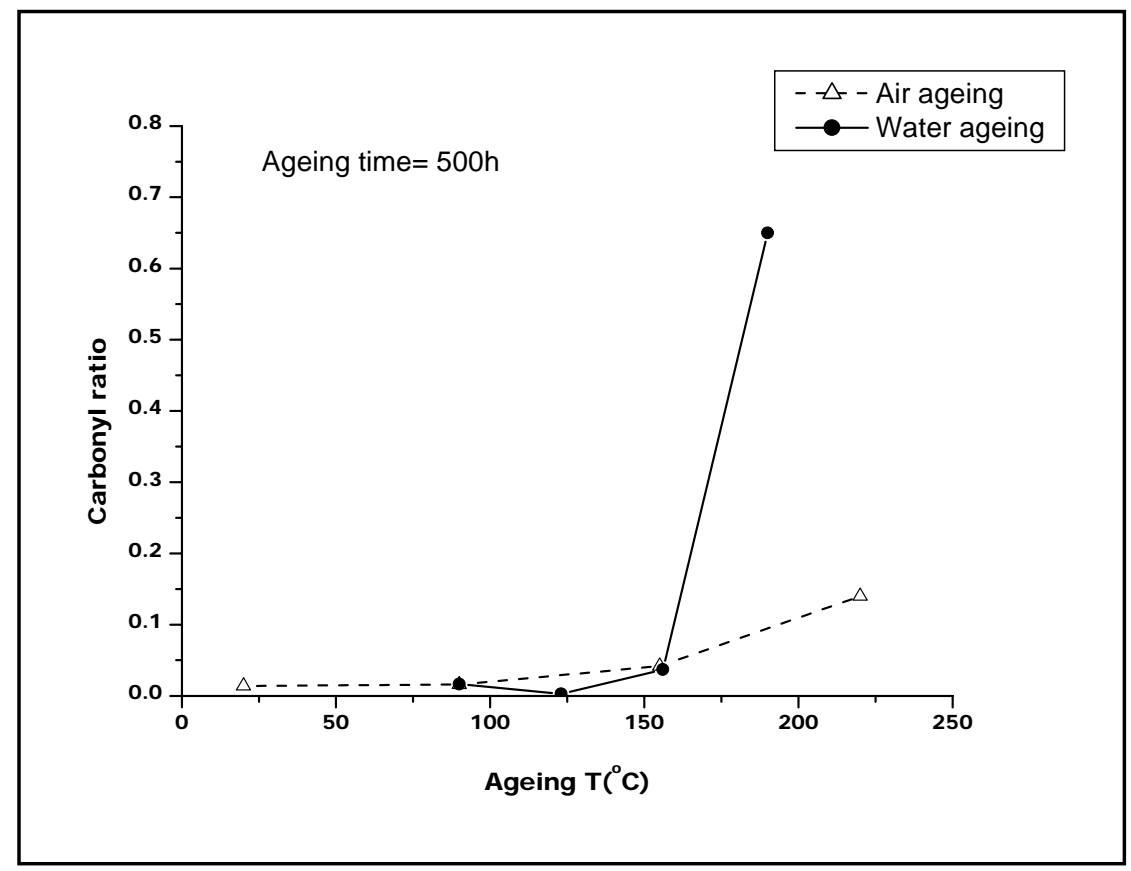

Fig.12a

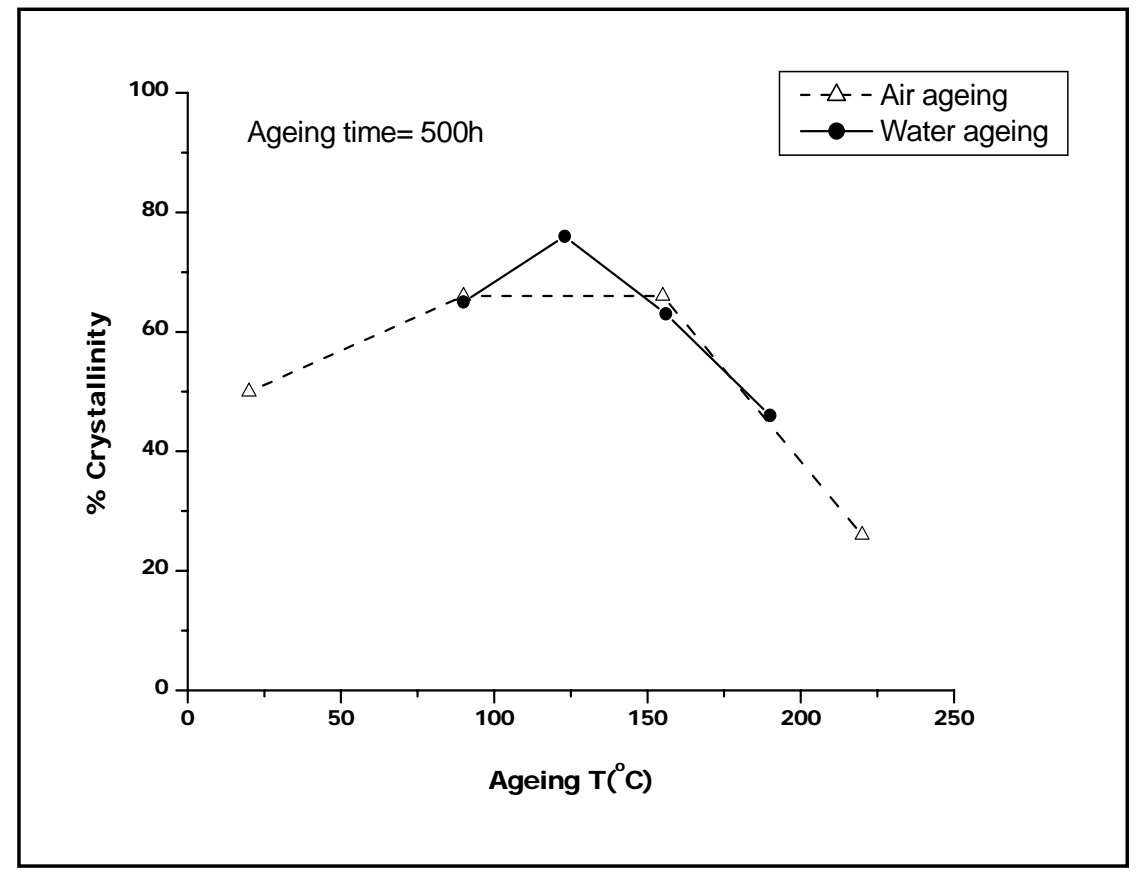

Fig.12b 